\title{
Effect of education, occupation and some lifestyle factors on common rheumatic complaints in a Swedish group aged $50-70$ years
}

\author{
L Jacobsson, F Lindgärde, R Manthorpe, K Ohlsson
}

\section{Abstract}

The relation between common rheumatic diseases such as osteoarthrosis, arthralgia without definite signs of osteoarthrosis, subacromial shoulder pain, different forms of tendinitis, low back pain and neck pain, and the level of formal education, occupational workload and some lifestyle factors were examined in 502 of 900 randomly selected subjects aged $50-70$ years.

The group with rheumatic complaints had a higher proportion of subjects with a lower level of formal education (less than or equal to eight years) by bivariate analysis. In multivariate analysis, the major risk factors were: a self rated heavy workload (odds ratio (OR) 6.4), sleep disturbance (OR 3.6), and advanced age (OR 2.0 per five year increase) for osteoarthrosis; a self rated heavy workload for subacromial shoulder pain (OR 5.4) and low back pain (OR 4.8); and a self rated heavy workload (OR 8.0) and female sex (OR 4.8) for neck pain. A self rated heavy workload was strongly correlated with a low level of formal education. A heavy workload (i.e. previous or present principal occupation) could only be confirmed in the groups with neck pain and low back pain on the basis of available occupational classification data. Neck pain was thus associated with occupations entailing repetitive tasks and awkward posture with respect to the neck, shoulders, and back. Low back pain was associated with occupations entailing awkward posture with respect to the neck, shoulders, and back, and occupations entailing exposure to vibration and heavy manual work.

It is concluded that, in a cross sectional sample of an elderly population, a low level of formal education and self rated heavy physical work are associated with the occurrence of adult rheumatic complaints, though the self rated heavy workload could only be verified in the groups with neck pain and low back pain. These correlations between heavy work and low back pain, and especially neck pain, suggest that successful prevention would mean a substantial economic gain to the community. Whether the level of education is a marker of risk factors other than a heavy occupational workload needs further evaluation.

(Ann Rheum Dis 1992; 51: 835-843)
As rheumatic complaints are common in industrialised countries, with estimates of their prevalence varying from 11 to $50 \%,{ }^{1-6}$ they represent a formidable economic burden to the community. ${ }^{5}$ In previous work based on the same population as this study, we found that $37 \cdot 8 \%$ of the population had musculoskeletal problems of over six weeks' duration during a twelve month period, the predominant disorders being subacromial shoulder pain, low back pain, neck pain, osteoarthrosis, and arthralgia without definite osteoarthrosis. ${ }^{4}$ Although much epidemiological data has been accumulated, ${ }^{6}$ the pathophysiology and aetiology of these disorders remain obscure. In case control studies, relations have been found between certain occupations and neck and shoulder disorders (for a review, see Hagberg and Wegman $^{8}$ ), low back pain (for a review, see Frymoyer $^{y}$ ), and even osteoarthrosis. ${ }^{10-13}$ In these studies, however, the cases have often been selected from special categories-for example, different industries-and the results cannot therefore be easily transferred to the general population, though they may yield valuable aetiological clues. Such drawbacks can be overcome in studies of random population samples, and a more realistic view obtained of the major aetiological factors in the general population.

Another proposed risk factor is a low level of formal education, not only for morbidity and mortality in disease in general, ${ }^{14}{ }^{15}$ but also for rheumatoid arthritis, ${ }^{16}$ and to some extent for more benign rheumatic complaints. ${ }^{17-19}$ Some of the possible links between a low level of education and the occurrence of adult rheumatic complaints, in addition to heavy occupational workloads, are increased environmental stress, deficient resistance to disease, or even factors of a hereditary nature.

The aims of this study were firstly to ascertain whether subjects with considerable rheumatic diseases in a random population - sample differ from control subjects with regard to education and living and working conditions, and if so, how; secondly, to see whether large subgroups of subjects with different rheumatic complaints (osteoarthrosis, arthralgia without definite osteoarthrosis, subacromial shoulder pain, different forms of tendinitis, neck pain) manifested similar patterns with regard to the same variables. 


\section{Patients and methods}

\section{POPULATION}

In 1984 a health survey entitled 'Malmö Food', supported by the World Health Organisation and the Swedish Research Council, was carried out at the section of preventive medicine at Malmö General Hospital. The main purpose of the study was to compare different methods of recording dietary habits. To this end, random samples of 450 women $(1 \cdot 45 \%$ of the female cohort), and 450 men $(1.67 \%$ of the male cohort), all living in the Malmö area and aged 50-70 years, were selected from population records. Of the 900 originally approached, questionnaire data were obtained from 693 $(77 \%)$ and $552(61 \%)$ participated in a health survey in 1984.

For this study (in 1985), the 1984 health survey group $(\mathbf{n}=552)$ was again invited to participate in a second health survey, and 445 agreed to do so. On this occasion, they were seen personally by one of this team $(\mathrm{LJ})$ who is a specialist in rheumatology and who diagnosed their rheumatic complaints. In the remaining 431 subjects (i.e. $900-445-24$ exclusions), the complaints were investigated by the same person $(\mathrm{LJ})$ in different ways and in the following order: by letter (46\%), telephone interview (33\%), and by scrutiny of case records $(11 \%)$. Case records were sought for in primary care clinics, hospital clinics, and from all local doctors specialising in rheumatology or orthopaedic surgery. Data on the presence of rheumatic complaints were thus obtained from $89 \%$ of these 431 subjects. When the presence of rheumatic complaints was suspected, the subject was invited to attend the clinic for examination; 57 of the study population were recruited in this way.

\section{Participants}

All those subjects personally investigated in 1985 are included in this study as responders $(n=445)$ and those who were found to have rheumatic symptoms by other means and were willing to participate $(n=57)$. Five hundred and two subjects were finally included in the study (women/men $=248 / 254$ ). Of these, 209 (women/ men $=112 / 97$; some subjects had more than one diagnosis) were classified as having considerable rheumatic complaints with the following distribution: osteoarthrosis $(n=46$, women $/ \mathrm{men}=$ $29 / 17)$; unspecified arthralgia $(n=36$, women/ men $=16 / 20)$; subacromial shoulder pain $(n=36$, women $/ \mathrm{men}=21 / 15)$; different forms of tendinitis $(n=22$, women $/$ men $=8 / 14)$; low back pain $(n=36$, women $/$ men $=11 / 25)$; neck pain $(n=35$, women $/$ men $=27 / 8$ ); definite or classical rheumatoid arthritis or other chronic arthritides $(n=12$, women $/ \operatorname{men}=6 / 6)$; and primary fibromyalgia $(n=8$, women $/$ men $=7 / 1)$. The prevalences in relation to sex, age, and joint distribution have been reported elsewhere. ${ }^{4}$

\section{Non-participants}

The non-participants $(n=398)$ did not differ from the other subjects with regard to mean age $(59.9 v 60.1$ years) or women/men ratio $(1.03 /$ 0.98 ). The subgroup of non-participants from which questionnaire data were obtained $(n=194)$ did not differ from participants with regard to such central variables as the proportions having a low formal education (65 $v 63 \%)$ or rating their previous physical workload as heavy (27v $25 \%)$.

\section{PHYSICAL EXAMINATIONS}

Since 1974, more than 40000 subjects have been examined at the section of preventive medicine at Malmö. This study followed the routines of previous screenings, the subjects being examined in the morning after a fast of at least 10 hours. The examination included a self administered questionnaire of 101 questions and measurements of the variables given in table 1 .

\section{QUESTIONNAIRE}

As shown in table 1, the questionnaire contained 101 questions. In this study emphasis was given to the following subgroups of questions.

\section{Sleep disturbances}

Three questions were posed: $(a)$ do you find it difficult to fall asleep in the evenings? $(b)$ do you often wake up late at night without being able to fall asleep again? (c) do you use sleeping pills more than three times a week?

If at least one question was answered positively, the subject was categorised as having sleep disturbance.

\section{Living conditions}

Marital status and the number of persons living together in the household were recorded. The following questions were posed: do you

Table 1 Variables assessed at the examination. The number of questions in each group in the questionnaire are given in parentheses

\begin{tabular}{l}
\hline Questionnaire (101): \\
Family conditions (2) \\
Living conditions (2) \\
Formal education (1) \\
Type of work (4) \\
Level of physical activity (6) \\
Occurrence of dry eyes or dry mouth (2) \\
Smoking and alcohol habits (7) \\
Pulmonary symptoms ( 3$)$ \\
Symptoms of coronary heart disease (4) \\
Presence of hypertension (2) \\
Presence of diabetes (2) \\
Bone fragility (2) \\
Sleep disturbances (3) \\
Gastrointestinal symptoms and weight (9) \\
Psychiatric disease (2) \\
Rheumatic diseases (3) \\
Presence of other disease(s) (4) \\
Drugs $(5$, including one about analgesics) \\
General health control and sick leave (2) \\
Heredity for cancer, coronary heart disease, stroke \\
and diabetes (34) \\
Physical examination: \\
Blood pressure (supine, after 10 minutes rest) \\
Pulse \\
Weight \\
Height \\
Skinfold thickness (5 cm above the elbow over the right \\
brachial triceps) \\
Blood or serum variables: \\
Triglycerides \\
Cholesterol \\
Erythrocyte sedimentation rate \\
Haemoglobin \\
Albumin \\
Urate \\
Glucose \\
Folic acid \\
Cobalamine \\
\end{tabular}


have a job or profession, do domestic work, study, receive disability pension, or old age pension? Do you live in a single family house (old, new), apartment house (old, new), nursing home, or in hospital? Living in a single family house (whether as tenant or owner) and apartment tenancy were adopted as indicators of high and low socioeconomic status respectively.

\section{Formal education}

Formal education was classified as low if the subject had only received the mandatory eight year basic schooling, or less.

\section{Physical activity at work}

The subjects were asked to assign themselves to one of four categories: 'easy work' (mainly sedentary), 'easy but entailing some movement', 'rather heavy', and 'heavy'. Illustrative examples of each category were given in the explanatory text of the questionnaire. In the analysis given in this paper, 'rather heavy' and 'heavy' physical activity were combined as one category: 'self rated heavy workload'. The question applied to the work situation during the preceding year and data were thus not acquired from those who did not work during this time (for example, due to retirement or disability). Answers were only obtained from $52 \%$ (the group with osteoarthrosis) to $69 \%$ (the group with subacromial shoulder pain) in the various subgroups of rheumatic diseases. The rate of response was similar $( \pm 3 \%)$, however, to that in control groups, except in the subgroup with subacromial shoulder pain, where it was slightly higher $(69 v$ $63 \%$ ) among subjects with symptoms and in the subgroup with low back pain where it was higher among control subjects (61 $v 76 \%)$.

\section{Assessment of occupational workload}

The participants' present or previous occupations were classified according to the 'Nordisk Yrkes klassificering'. ${ }^{20}$ One of the team (KO), an experienced physiotherapist, subsequently classified the different occupations according to eight features or items, the classification being performed blindly without any knowledge of the pain or disease suffered by the subjects. The eight items evaluated were: (1) lifting ( $r=0.53$, $\mathrm{p}<0.001$ ) (farmer, building worker); (2) standing, walking, pulling or pushing $(r=0.53$, $\mathrm{p}<0.001$ ) (assistant nurse, postman); (3) repetitive or static work, or both $(r=0.07, \mathrm{NS})$ (cashier, data entry operators); (4) awkward working posture with respect to the neck or shoulder, or both $(r=0.16, p<0.01)$ (dentist, welder); (5) awkward working posture with respect to the back or legs, or both $(r=0 \cdot 50$, $\mathrm{p}<0.001$ ) (plate worker, bricklayer); (6) heavy work with hands or forearms, or both $(r=0.44$, $\mathbf{p}<0.001$ ) (blacksmith, plate worker); (7) exposure to whole body vibrations $(r=0.03$, NS) (truck driver, farmer); and (8) exposure to hand vibrations $(r=0.25, p<0.001)$ (machine operator, blacksmith).

Each item was rated on a four point scale $(0-3)$, with 3 as maximum exposure. Examples of occupations given the rating 3 ( 2 for hand vibrations) are given in the above list in parentheses. Such ratings were obtained for over $90 \%$ of every subgroup except the low back pain subgroup where they were obtained for $84 \%$.

The correlation coefficients between each feature and the self rated heavy workload are also given. The two different ways of measuring heavy physical workload correlate significantly in most features. With respect to repetitive and static work and exposure to whole body vibration, however, the two methods give deviating results with an underestimation of the physical workload when rated by the subjects themselves.

\section{DIAGNOSIS}

Considerable rheumatic complaints were considered to be present in the event of pain or stiffness of the joints, continuous or intermittent, of more than six weeks' duration within the preceding 12 month period. Thus we excluded less significant symptoms. The remainder of the population served as controls.

Osteoarthrosis in the distal and proximal interphalangeal joints was diagnosed when palpable osteophytes were present, and osteoarthrosis of the first metatarsophalangeal joint when hallux valgus (definite lateral deviation of the base joint of the big toe) and limitation of movement was present. Osteoarthrosis of the first carpometacarpal joints, or the knee, hip, elbow, and ankle joints was diagnosed when a radiological examination showed cartilage reduction. The degree of radiological osteoarthrosis was not classified.

Unspecified arthralgia was considered to be present when clinical and radiological investigations failed to show any sign of osteoarthrosis or inflammation. Of those classified in this group, $28 \%(10 / 36)$ were subjects where a diagnosis of osteoarthrosis would have required radiological investigation, which could not be performed due to poor patient compliance.

Subacromial shoulder pain was diagnosed as pain interpreted as coming from the periarticular tissue of the shoulder and located just below the acromion. Different forms of tendinitis were defined as distinct tenderness over the insertion of the tendon, together with increased pain when active force was applied to the tendon against resistance. Low back pain, with or without sciatica, was considered to be present when pain was localised to the lumbar region as described by Andersson. ${ }^{21}$ Neck pain, with or without cervical brachalgia, was diagnosed when pain was located within the triangle formed by the occipital process, the medial corner of scapula, and the acromion.

Radiological examination was not routinely performed either in the group with shoulder pain or in the groups with back pain.

\section{STATISTICAL METHODS}

The $\chi^{2}$ test with Yates's correction and Student's $t$ test were used when comparing groups. When the total frequencies were too small for this test, Fisher's exact two tailed test was used.

In bivariate analysis, the different subgroups of rheumatic complaints were compared with 
controls (selected from that part of the population which did not have symptoms of over six weeks' duration during the previous 12 month period) matched for sex and age (difference less than one year). The ratio of control subjects to cases studied was 3:1 for osteoarthrosis and neck pain, 4:1 for low back pain, 5:1 for unspecified arthralgia and subacromial shoulder pain, 8:1 for tendinitis, and 3:5 for rheumatic complaints as a whole.

In bivariate analysis, nine variables (age, sex, education, self rated heavy workload, body mass index (BMI), tobacco consumption, sleep disturbance, living in a single family house, and living alone) were selected as possible determinants of the risk of developing different rheumatic diseases $(p<0 \cdot 3)$. These variables were then compared in stepwise logistic regression analysis (the CATMOD subroutine in the statistical analysis system, backward elimination) and the odds ratios (ORs with $95 \%$ confidence interval) were calculated for those variables that were independently and significantly correlated with the different rheumatic groups.

As the variable self rated heavy workload applied to working demands during the preceding 12 month period, those who did not work during this time (due to retirement or disability) were excluded from the analysis of this variable. The proportion of the different groups included in the multivariate analysis thus varied from $52 \%$ in the group with osteoarthrosis to $69 \%$ in the group with subacromial shoulder pain.

Data on occupational exposure were analysed with the Wilcoxon rank sum test.

\section{Results}

\section{RHEUMATIC COMPLAINTS}

The figure (panel A) shows that the rheumatic diseases group as a whole was characterised by a lower level of formal education $(p<0.001)$, an increased incidence of self rated heavy workload $(p<0.001)$, poorer living conditions (for example, a greater proportion of apartment tenants $)(\mathrm{p}<0.05)$, and less subjects reporting living alone $(p<0.05)$, compared with age and sex matched control subjects.

Subjects with symptoms did not differ from control subjects with respect to $\mathrm{BMI}$, tobacco consumption, serum lipids, or the frequency of sleep disturbances, though the latter tended to be more common among symptomatic subjects.

In the multivariate analysis the occurrence of rheumatic complaints was found to be independently related to self rated heavy workload (OR $2 \cdot 8,95 \%$ confidence interval 1.9 to $4 \cdot 0$; $\mathrm{p}<0.007$ ), living alone (protective effect, $O R$ $2 \cdot 5,95 \%$ confidence interval $1 \cdot 7$ to $3 \cdot 7 ; p<0.02)$, and living in a single family house (protective effect, OR $2 \cdot 0,95 \%$ confidence interval $1 \cdot 4$ to $2 \cdot 7 ; \mathrm{p}<0.04)$.

Table 2 shows that an analysis of previous or present principal occupations indicated the occurrence of rheumatic diseases to correlate with occupations charcterised by repetitive or static work $(p<0.02)$, awkward working posture with respect to the neck and shoulders $(p<0.009)$ and back and legs $(p<0.02)$, as well as occupations characterised by exposure to hand vibration $(p<0.01)$.

\section{OSTEOARTHROSIS}

The group with osteoarthrosis (panel $\mathrm{B}$, figure) had a lower level of formal education $(p<0.06)$, a higher occurrence of self rated heavy workload $(\mathrm{p}<0.001)$, and a tendency toward poorer living conditions ( $24 v 31 \%$ ) compared with age and sex matched control subjects.

For the osteoarthrosis subgroup as a whole, BMI values were higher $\left(26.6 v 24.9 \mathrm{~kg} / \mathrm{m}^{2}\right.$; $\mathrm{p}<0.01$ ), a trend even more pronounced among those with osteoarthrosis of the knees $(n=19$, $\left.27 \cdot 3 v \mathrm{n}=133,24 \cdot 8 \mathrm{~kg} / \mathrm{m}^{2} ; \mathrm{p}<0 \cdot 007\right)$ but absent among those with osteoarthrosis in the hands only $\left(\mathrm{n}=24,24.6 v \mathrm{n}=120,24 \cdot 7 \mathrm{~kg} / \mathrm{m}^{2}\right.$; NS), all compared with age and sex matched control subjects.

Neither tobacco consumption nor serum lipids differed between subjects with symptoms and control subjects, but there was a higher proportion of subjects with sleep disturbance $(p<0.007)$ among those with symptoms.

In multivariate analysis, the occurrence of osteoarthrosis was independently related to self rated heavy workload (OR 6.4, 95\% confidence interval 3.7 to $11.2 ; \mathrm{p}<0.002$ ), sleep disturbance (OR 3.6, 95\% confidence interval $2 \cdot 2$ $5.8 ; \mathrm{p}<0.009$ ), and advanced age (OR 2.0 for each five year increment, $95 \%$ confidence intervals 1.5 to $2.6 ; p<0.009$ ). Significantly increased occupational workload requirements could not be verified, however (table 2).

\section{UNSPECIFIED ARTHRALGIA}

The subjects with arthralgia had a similar pattern of lower formal education $(p<0 \cdot 007)$, a higher occurrence of self rated heavy workload $(22 v 13 \%)$ and poorer living conditions (19v $34 \%$ ) (panel C, figure).

There was a significant increase in tobacco consumption $(8.1 v 4.2 \mathrm{~g} / \mathrm{day} ; \mathrm{p}<0.03)$. Serum concentrations of cholesterol tended to be higher $(6.40 v 6.00 \mathrm{mmol} / \mathrm{l}$; NS), as did those of triglycerides $(1.69 v 1.32 \mathrm{mmol} / \mathrm{l} ; \mathrm{NS})$, and the proportion of subjects with sleep disturbances (39 $v 31 \%)$.

We found no independent relation in multivariate analysis, nor any increase in occupational workload, except for a slight increase of previous or present occupations characterised by awkward posture with respect to the back and legs $(\mathrm{p}<0.03$; table 2$)$.

\section{SUBACROMIAL SHOULDER PAIN}

The group with subacromial shoulder pain had a similar pattern to that of the other groups, with a low level of formal education (61 $v 49 \%$ ), a high occurrence of self rated heavy workload $(\mathrm{p}<0.001)$, poorer living conditions $(28 v 33 \%)$, and a tendency towards a higher proportion of subjects with sleep disturbances (44 $v 31 \%$ ) (panel D, figure).

Data for tobacco consumption, serum lipids, and BMI did not differ from those for control subjects.

Multivariate analysis showed relations to exist between subacromial shoulder pain and self rated heavy workload (OR $5 \cdot 4,95 \%$ confidence interval 3.4 to $8 \cdot 6 ; p<0.005$ ). No increase in 

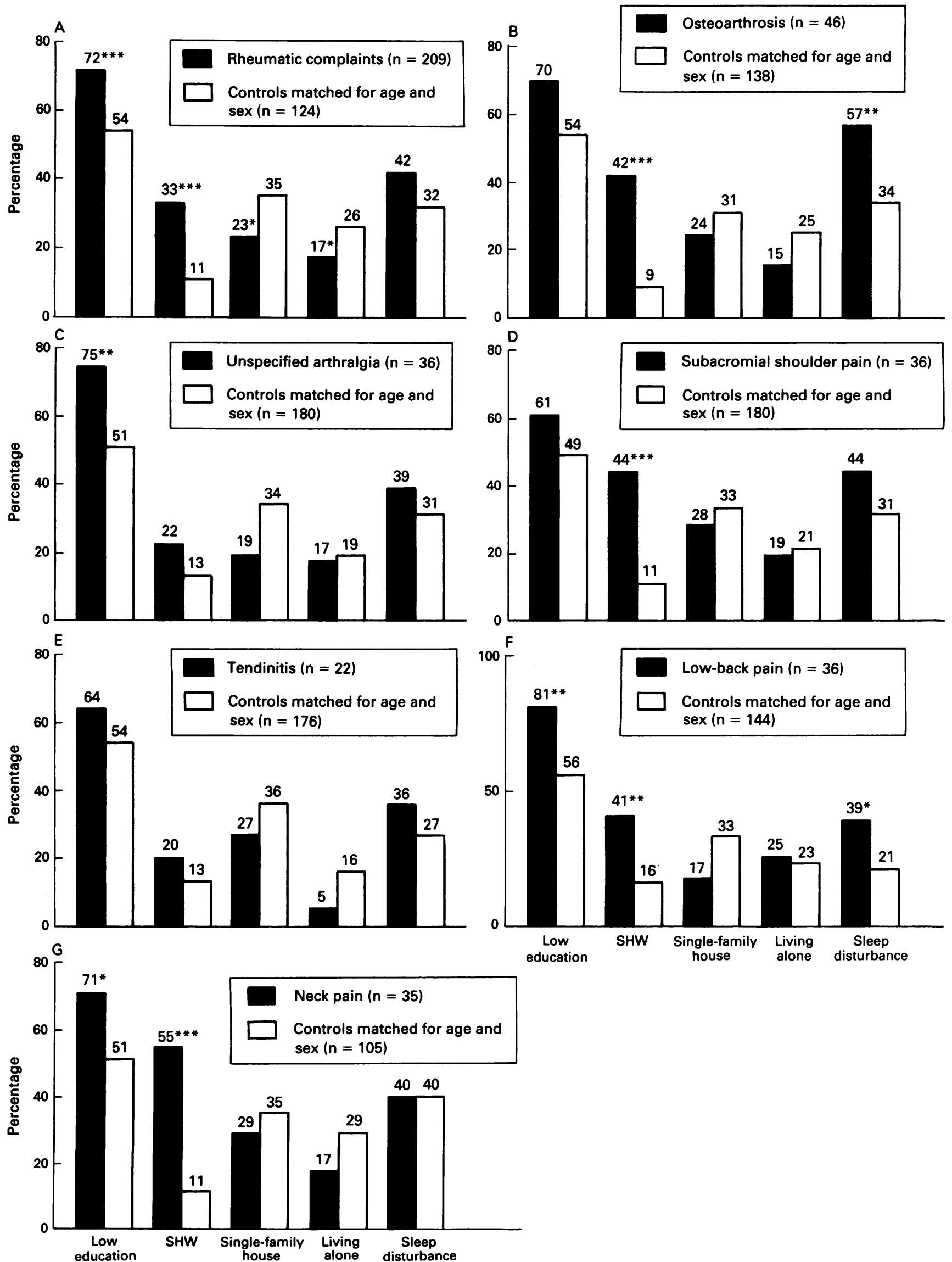

Data for subjects with rheumatic complaints (as a whole and by subgroups), comparcd with age and sex matched control subjects with respect to the following variables: level of education, self rated heavy workload ( $S H W \dot{W}$ ), living in a single family housc (as opposed to apartment tenancv), living alone, and sleep disturbances. The bars represent percentages of the respective groups. $p<0.05 ; p<0.01 ;$ and $p<0.001$ 
Table 2 Distribution of groups with different rheumatic complaints compared with age and sex matched controls by eight Distributions are given as percentages of the total number of subjects in the respective groups, given in the first column

\begin{tabular}{|c|c|c|c|c|c|c|c|c|c|c|c|c|c|c|c|c|c|}
\hline \multirow[t]{2}{*}{ Subgroup } & \multirow[t]{2}{*}{ Subjects } & \multicolumn{4}{|c|}{ Heavy lifing } & \multicolumn{4}{|c|}{$\begin{array}{l}\text { Much standing/ } \\
\text { walking }\end{array}$} & \multicolumn{4}{|c|}{ Repetitive/static } & \multicolumn{4}{|c|}{$\begin{array}{l}\text { Awkward working } \\
\text { position for } \\
\text { neck or shoulders }\end{array}$} \\
\hline & & 0 & $I$ & 2 & 3 & 0 & 1 & 2 & 3 & 0 & $l$ & 2 & 3 & 0 & $I$ & 2 & 3 \\
\hline \multirow[t]{2}{*}{$\overline{\mathrm{RC}}$} & Case $(n=192)$ & 38 & 20 & 40 & 3 & 31 & 18 & 27 & 25 & 49 & 9 & 21 & $21 t$ & 16 & 28 & 30 & $26 \ddagger$ \\
\hline & Control $(n=118)$ & 52 & 9 & 35 & 4 & 47 & 12 & 14 & 28 & 60 & 14 & 12 & 14 & 21 & 39 & 22 & $17^{\circ}$ \\
\hline \multirow{2}{*}{ OA } & Case $(n=44)$ & 41 & 16 & 43 & 0 & 34 & 16 & 20 & 30 & 50 & 11 & 25 & 14 & 9 & 39 & 36 & 16 \\
\hline & Control $(n=130)$ & 47 & 14 & 36 & 3 & 39 & 18 & 15 & 28 & 62 & 12 & 15 & 12 & 24 & 35 & 26 & 15 \\
\hline \multirow[t]{2}{*}{ UA } & Case $(n=33)$ & 39 & 18 & 42 & 0 & 33 & 15 & 27 & 24 & 48 & 9 & 24 & 18 & 15 & 30 & 30 & 24 \\
\hline & Control $(n=171)$ & 53 & 16 & 27 & 4 & 47 & 15 & 19 & 19 & 62 & 11 & 15 & 13 & 27 & 36 & 19 & 18 \\
\hline \multirow[t]{2}{*}{ SA } & Case $(n=33)$ & 39 & 24 & 36 & 0 & 30 & 21 & 27 & 21 & 48 & 15 & 12 & 24 & 21 & 30 & 24 & 24 \\
\hline & Control $(n=169)$ & 52 & 11 & 35 & 2 & 46 & 13 & 17 & 24 & 59 & 12 & 13 & 15 & 25 & 34 & 23 & 18 \\
\hline \multirow{2}{*}{$\mathrm{TE}$} & Case $(n=20)$ & 40 & 20 & 35 & 5 & 35 & 15 & 20 & 30 & 55 & 10 & 20 & 15 & 20 & 35 & 30 & 15 \\
\hline & Control $(n=167)$ & 50 & 16 & 29 & 4 & 46 & 13 & 20 & 21 & 63 & 13 & 15 & 10 & 28 & 35 & 23 & 13 \\
\hline \multirow[t]{2}{*}{ LB } & Case $(n=31)$ & 29 & 23 & 35 & 13 & 26 & 13 & 42 & 19 & 58 & 10 & 23 & 10 & 16 & 32 & 26 & $26 \dagger$ \\
\hline & Control $(n=135)$ & 48 & 16 & 30 & 5 & 45 & 11 & 22 & 21 & 65 & 11 & 16 & 7 & 30 & 36 & 19 & 15 \\
\hline \multirow[t]{2}{*}{ NP } & Case $(n=32)$ & 41 & 9 & 50 & 0 & 34 & 13 & 22 & 31 & 25 & 10 & 22 & 440 & 9 & 9 & 34 & $47 \S$ \\
\hline & Control $(n=100)$ & 52 & 9 & 35 & 4 & 47 & 12 & 14 & 28 & 60 & 14 & 12 & 14 & 25 & 34 & 21 & 20 \\
\hline
\end{tabular}

(RC) whole group with rheumatic complaints, (OA) osteoarthrosis, (UA) unspecified arthralgia, (SA) subacromial, shoulder pain,

(TE) tendinitis, (LB) low back pain, (NP) neck pain.

tp $<0.05$.

$\underset{\mathrm{p}<0.001}{+\mathrm{p}<}$

occupational workload could be found, however (table 2).

\section{TENDINITIS}

The group with different forms of tendinitis, which is a more heterogeneous group than the others, did not differ significantly with respect to the level of formal education, the frequency of self rated heavy workload ( $20 v 13 \%$ ), poorer living conditions ( $27 v 36 \%$ ), or the proportion of those with sleep disturbances, though they tended to deviate from control subjects in these respects in the same manner as the other subgroups with symptoms (panel E, figure).

There were no differences with respect to BMI values, serum concentrations of cholesterol or triglycerides, nor tobacco consumption compared with matched controls. We found no independent associations in multivariate analysis, nor any increase in occupational workload (table 2).

\section{LOW BACK PAIN}

The group with low back pain also had a similar pattern, with a low level of formal education $(\mathrm{p}<0.01)$, a high occurrence of self rated heavy workload $(p<0.01)$, and a low proportion of subjects living in single family houses (17v $33 \%$ ) (panel $\mathrm{F}$, figure). Tobacco consumption was significantly higher $(9.7 \quad v \quad 4.2$ g/day; $\mathrm{p}<0.02$ ), but not BMI values nor serum concentrations of cholesterol or triglycerides.

Just as in the group with osteoarthrosis, there was an increased proportion of subjects with sleep disturbances $(p<0.03)$ among those with symptoms.

Multivariate analysis showed the occurrence of low back pain to be independently related to self rated heavy workload (OR $4 \cdot 8,95 \%$ confidence interval 2.9 to $7 \cdot 8 ; \mathrm{p}<0.001$ ).

Analysis of previous or present principal occupations (table 2) showed correlations to exist between low back pain and occupations characterised by awkward posture with respect to the neck and shoulders $(p<0.05)$ and back and legs $(\mathrm{p}<0.05)$, in addition to occupations including heavy manual work and exposure to hand vibration $(\mathrm{p}<0.05)$.

\section{NECK PAIN}

The group with neck pain was also characterised by the same pattern of low education $(\mathrm{p}<0.05)$, high self rated heavy workload $(\mathrm{p}<0.001)$, and poorer living conditions (29v $35 \%$ ) as the previous subgroups, though values for tobacco consumption, serum concentrations of cholesterol and triglycerides, BMI values, or the occurrence of sleep disturbances did not differ from those of control subjects (panel G, figure). Multivariate analysis showed the occurrence of neck pain to be independently related to self rated heavy workload (OR $8.0,95 \%$ confidence interval 4.7 to $13.6 ; \mathrm{p}<0.001$ ) and female sex (OR $4 \cdot 8,95 \%$ confidence interval $3 \cdot 0$ to $10.3 ; \mathrm{p}<0.001)$.

Analysis of previous or present principal occupations (table 2) showed neck pain to be correlated with occupations characterised by repetitive or static work tasks $(\mathrm{p}<0.001)$ and awkward posture with respect to the neck and shoulders $(p<0.001)$ and back and legs $(\mathrm{p}<0 \cdot 007)$.

\section{OTHER ASSOCIATIONS}

In none of the groups with symptoms was there any significant or consistent abnormalities with respect to the hip to waist ratio, alcohol habits, marital status, blood pressure in untreated patients, whole blood haemoglobin, serum concentrations of urate, albumin or creatinine, or hereditary for hypertension, coronary heart disease, stroke, diabetes or cancer. There were no differences with respect to frequency of disability pensions, except for an increase in the low back pain subgroup (19v $4 \% ; \mathrm{p}<0.01)$.

The level of formal education was strongly correlated with self rated heavy workload in the rheumatic complaints group as a whole $\left(\chi^{2}=16 \cdot 3 ; p<0.001\right)$. Of those reporting heavy 
different features of heavy workload conditions (for details, see text) rated on a 0 to 3 scale.

\begin{tabular}{|c|c|c|c|c|c|c|c|c|c|c|c|c|c|c|c|}
\hline \multicolumn{4}{|c|}{$\begin{array}{l}\text { Awkward working } \\
\text { position for } \\
\text { back or legs }\end{array}$} & \multicolumn{4}{|c|}{$\begin{array}{l}\text { Heavy work } \\
\text { for hands or } \\
\text { forearms }\end{array}$} & \multicolumn{4}{|c|}{$\begin{array}{l}\text { Whole body } \\
\text { vibrations }\end{array}$} & \multicolumn{4}{|c|}{$\begin{array}{l}\text { Hand } \\
\text { vibrations }\end{array}$} \\
\hline 0 & 1 & 2 & 3 & 0 & $I$ & 2 & 3 & 0 & $I$ & 2 & 3 & 0 & $l$ & 2 & 3 \\
\hline $\begin{array}{r}14 \\
29 \\
7 \\
25 \\
18 \\
29 \\
18 \\
28 \\
25 \\
31 \\
16 \\
33 \\
0 \\
27\end{array}$ & $\begin{array}{l}31 \\
25 \\
41 \\
28 \\
21 \\
32 \\
36 \\
28 \\
25 \\
28 \\
23 \\
24 \\
31 \\
25\end{array}$ & $\begin{array}{l}34 \\
32 \\
41 \\
32 \\
42 \\
32 \\
21 \\
31 \\
25 \\
26 \\
39 \\
28 \\
41 \\
31\end{array}$ & $\begin{array}{l}20 \dagger \\
14 \\
11 \\
16 \\
18 \dagger \\
8 \\
24 \\
13 \\
25 \\
15 \\
23 \dagger \\
15 \\
28 \ddagger \\
17\end{array}$ & $\begin{array}{l}48 \\
58 \\
48 \\
57 \\
45 \\
64 \\
52 \\
60 \\
50 \\
59 \\
39 \\
56 \\
44 \\
62\end{array}$ & $\begin{array}{l}34 \\
30 \\
36 \\
32 \\
45 \\
25 \\
33 \\
28 \\
20 \\
25 \\
29 \\
28 \\
34 \\
28\end{array}$ & $\begin{array}{r}15 \\
12 \\
14 \\
10 \\
6 \\
11 \\
9 \\
11 \\
30 \\
13 \\
26 \\
15 \\
19 \\
9\end{array}$ & $\begin{array}{l}3 \\
0 \\
2 \\
2 \\
3 \\
1 \\
6 \\
1 \\
0 \\
3 \\
6 \dagger \\
1 \\
3 \dagger \\
1\end{array}$ & $\begin{array}{r}94 \\
92 \\
91 \\
94 \\
91 \\
91 \\
97 \\
95 \\
95 \\
89 \\
87 \\
87 \\
100 \\
97\end{array}$ & $\begin{array}{l}1 \\
4 \\
2 \\
2 \\
0 \\
4 \\
0 \\
2 \\
0 \\
5 \\
3 \\
5 \\
0 \\
0\end{array}$ & $\begin{array}{r}5 \\
4 \\
7 \\
4 \\
9 \\
5 \\
3 \\
3 \\
5 \\
5 \\
10 \\
7 \\
0 \\
3\end{array}$ & $\begin{array}{l}0 \\
0 \\
0 \\
0 \\
0 \\
0 \\
0 \\
0 \\
0 \\
0 \\
0 \\
0 \\
0 \\
0\end{array}$ & $\begin{array}{l}78 \\
89 \\
82 \\
88 \\
78 \\
84 \\
79 \\
88 \\
80 \\
80 \\
53 \\
79 \\
88 \\
94\end{array}$ & $\begin{array}{r}8 \\
8 \\
9 \\
5 \\
13 \\
9 \\
6 \\
6 \\
0 \\
10 \\
17 \\
11 \\
3 \\
3\end{array}$ & $\begin{array}{r}14 \\
3 \\
9 \\
6 \\
9 \\
8 \\
15 \\
7 \\
20 \\
10 \\
30 \\
10 \\
9 \\
3\end{array}$ & $\begin{array}{l}0 \ddagger \\
0 \\
0 \\
0 \\
0 \\
0 \\
0 \\
0 \\
0 \\
0 \\
0 \dagger \\
0 \\
0 \\
0\end{array}$ \\
\hline
\end{tabular}

workloads, $88 \%$ had a low level of education compared with $61 \%$ of those who did not report a heavy workload, and $17 \%$ of those with a low level of education reported heavy workloads compared with $4 \%$ of those with a higher level of education.

\section{Discussion}

In the group with rheumatic complaints as a whole and in the various subgroups (neck pain, low back pain, osteoarthrosis, arthralgia, subacromial shoulder pain, and tendinitis), we found the occurrence of such disorders to be related to a low level of formal education and self rated heavy workloads. A heavy occupational workload could, however, only be verified in the groups with neck pain and low back pain on the basis of earlier occupational classification data (as described under Methods).

A low level of formal education has previously been reported to be associated with an increased risk for musculoskeletal disorders, ${ }^{3}$ 17-19 22 hypertension, ${ }^{23}$ and coronary heart disease. ${ }^{24}$ In fact, relations seem to exist between a low level of education and most diseases, except for malignant diseases and multiple sclerosis. ${ }^{14} \mathrm{~A}$ low level of formal education may not just be associated with an increased risk of contracting a chronic disease, however, but also with an increase in subsequent morbidity and mortality, as has been especially documented for coronary heart disease and rheumatoid arthritis. ${ }^{1625}$

In view of the relation between the occurrence of rheumatic complaints and a low level of education and self rated heavy workloads found in our study, and as the level of education is determined early in life, it would seem reasonable to suppose a low level of education to result in adult rheumatic disease mainly by predisposing the subject for employment in an occupation with heavy physical demands. It should be born in mind, however, that heavy occupational workloads could only be verified in the groups with neck pain and low back pain.

We found neck pain to be highly correlated with occupations containing repetitive or static work tasks and awkward work posture with respect to the neck, shoulders, back, and legs. In case control studies, others have found neck tension syndromes to be over represented among certain occupations with similar physical demands, such as film rolling and lamp assembly, ${ }^{26}$ and among women industrial workers, ${ }^{27}{ }^{28}$ typists and data entry operators. ${ }^{29}$ Epidemiological studies on the general population are lacking, to the best of our knowledge, however.

In our study, low back pain was associated with occupations entailing awkward posture with respect to neck, shoulders, lower back and legs, or exposure to hand vibrations and heavy manual work. In previous studies of selected cohorts, low back pain has been linked to occupational factors such as repetitive lifting 3031 and exposure to vibration ${ }^{32} 33$; and in studies on samples of the general population, low back pain has been found to be correlated to mining ${ }^{34}$ and such occupational requirements as lifting and pushing. ${ }^{35-37}$ In these latter studies, in contrast to our study, the workload data derived solely from self ratings by the subjects.

For the other major subgroups of rheumatic complaints, we found no significant correlation with verified heavy workloads. Such relations might nonetheless be present in subgroups, however, as the subacromial shoulder pain, tendinitis, and osteoarthrosis subgroups are heterogeneous. Thus, for example, in previous studies rotator cuff tendinitis of the shoulder has been found to be clearly over represented among certain occupations, ${ }^{38}$ especially shipyard welders ${ }^{39}$ and plate workers, ${ }^{40}$ and osteoarthrosis of the fingers, ${ }^{11}$ knees, ${ }^{13}$ and hips ${ }^{12}$ to be over represented in specific occupational groups. Moreover, the approach used by us with retrospective estimation of the workloads may be flawed by some measure of uncertainty. The optimum approach would be to evaluate prospectively the ergonomic demands of specific subjects at their work stations.

Such reservations notwithstanding, the fact that, in our study, we nevertheless found relations to exist between occupational demands and neck pain and low back pain suggests that these relations are strong and general. If back problems are to be reduced in the community, it would thus seem reasonable to invest resources in reducing such occupational demands. Apart from a salutary reduction in personal suffering, such prevention would probably mean considerable economic gain to the community.

Although its limiting effect on the choice of occupation is the most likely explanation of the relation between a low level of formal education and the occurrence of adult rheumatic complaints, alternative contributing mechanisms are also possible.

First, a low level of education might be related to increased disease susceptibility as a marker of a deficient social support ${ }^{+1}$ or impaired coping and problem solving capacity, ${ }^{42}$ leading to a lower resistance to disease or inadequacy in handling stress in adult life, or both. We did not specifically attempt to quantify the participants' social networks, but the fact that there were actually fewer subjects living alone in the groups with symptoms does not support the idea that they were deficient in this respect.

Sleep disturbances were generally more com- 
mon in all the subgroups with rheumatic diseases than among control subjects, though the difference was significant in the osteoarthrosis and low back pain subgroups only. This increase may, of course, to some extent have been an effect of the increased pain accompanying the rheumatic disease. Sleep disturbance is, however, also an indicator of chronic and subacute socioeconomic distress, such as stress at work and poor control over the occupational setting, ${ }^{43}$ factors that might possibly increase susceptibility to rheumatic diseases and diseases in general. Sleep disturbance has already been suggested to be crucially involved in the development of symptoms in primary fibromyalgia ${ }^{44}$; perhaps it also enhances symptoms in osteoarthrosis.

Secondly, a low level of education might be associated with a lifestyle characterised by other environmental factors, besides heavy occupational workload requirements, which might increase the risk of adult rheumatic diseases. An example of this might be the slightly higher tobacco consumption in the arthralgia and low back pain subgroups.

Thirdly, by predisposing for a poorer economic situation, a low level of education might also entail less access to medical care, and thus a higher occurrence of disease. Owing to the Swedish social insurance system, however, which guarantees practically free medical services to all citizens, it would seem less likely that any appreciable differences exist between groups with different levels of education. The level of education might, however, influence the liability to take advantage of such benefits.

Finally (and theoretically), another explanation might be genetic, though the rheumatic syndromes discussed here are not commonly considered to be of a hereditary nature. We found no increase in occurrence among first degree relatives of other diseases that are, at least to some extent, considered to have hereditary components, such as diabetes mellitus, coronary heart disease, stroke, hypertension, or malignant disease, however. Thus these findings provide no support for the idea of familial aggregation of heterozygosity predisposing for disease. This needs to be interpreted with caution in view of the great risk of bias in retrospective assessments based on questionnaire answers.

To sum up, in a cross sectional population sample, we found most adult rheumatic complaints to be associated with a low level of education and a heavy self rated workload, though heavy workloads could only be verified in the neck pain and low back pain subgroups. Prevention of abnormal workloads might thus be beneficial in reducing the overall prevalence of such disorders as neck pain and low back pain, and in cutting the formidable economic burden that they represent for the community. Whether the level of education is a marker of risk factors other than occupational needs further evaluation.

This study was supported by grants from the Swedish Rheumatism Association, the Alfred Osterlund Trust, and the Albert Păhlson Trust. We thank Jan-Ake Nilsson for help with the statistics.
I Bjelle A, Allander E, Lundquist B. Geographic distribution of rheumatic disorders and working conditions in Sweden. Scand F Soc Med 1981; 9: 119-26.

2 Laine V. Rheumatic complaints in an urban population in Finland. Acta Rheumatol Scand 1962; 8: 81-8.

3 Cunningham L, Kelsey J. Epidemiology of musculoskeletal impairments and associated disability. Am $\mathcal{F}$ Public Health 1984; 74: 574-9.

4 Jacobsson L, Manthorpe R, Lindgräde F. The commonest rheumatic complaints of over six weeks duration in a rheumatic complaints of over six weeks duration in a
twelve-month period in a defined Swedish population. twelve-month period in a defined $S$
Scand $\mathcal{F}$ Rheumatol $1989 ; 18: 353-60$.

5 Allander E, Behrend T, Henrard J C, et al. Rheumatology in perspective. The epidemiological view. Scand $\mathcal{F}$ Rheumatol Suppl 1982; 46: 1-49.

6 Kelsey J L, Hochberg M C. Epidemiology of chronic musculoskeletal disorders. Annu Rev Public Health 1988; 9: 379-401.

7 Leistner K, Wessel G, Allander E. Medium-term trends in the occurrence of rheumatic diseases in European countries. Scand F Rheumatol 1986; 15: 206-18.

8 Hagberg M, Wegman D H. Prevalence rates and odds ratios of shoulder-neck diseases in different occupational groups. Br f Ind Med 1987; 44: 602-10.

9 Frymoyer J. Back pain and sciatica. N Engl F Med 1988; 318 : 291-300.

10 Felson D T. Epidemiology of hip and knee arthrosis. Epidemiol Rev 1989; 10: 1-28.

11 Lawrence J S. Rheumatism in cotton operatives. $\mathrm{Br} \mathrm{F}$ Ind Med 1961; 18: 270-6.

12 Axmacher B, Lindberg H. Coxarthrosis in farmers. Clin Orthop. In press.

13 Lindberg $\mathrm{H}$, Montgomery $\mathrm{F}$. Heavy labour and the occurrence of gonarthrosis. Clin Orthop 1986; 203: 273-5.

14 Pincus T, Callahan L, Burkhauser R. Most chronic diseases are reported more frequently by individuals with fewer than 12 years of formal education in the age 18-64 United than 12 years of formal education in the age 18-64

15 Jenkins J D. Low education: a risk factor for death. N Engl f Med 1978; 299: 95-7.

16 Pincus T, Callahan L. Formal education as a marker for increased mortality and morbidity in rheumatoid arthritis. f Chronic Dis 1985; 38: 973-84.

17 Bergenudd $\mathbf{H}$, Nilsson $B$, Back pain in middle age: occupational workload and psychological factors: an epidemiological survey. Spine 1988; 13: 58-60.

18 Cobb S, Kasl S V, Chen E, Christenfeld R. Some psychological and social characteristics of patients hospitalized for rheumatoid arthritis, hypertension, and duodenal ulcer. f Chronic Dis 1965; 18: 1259-78.

19 Pincus T, Mitchell J M, Burkhauser R V. Substantial work disability and earnings losses in individuals less than age 65 with osteoarthritis: comparisons with rheumatoid arthritis. $\mathcal{F}$ Clin Epidemiol 1989; 42: 449-57.

20 Scandinavian Occupational Classification. Arbetsmarknads styrelse, Allmänna förlaget, Stockholm, 1978.

21 Andersson J A D. Problems of classification of low back pain Rheumatol Rehabil 1977; 16: 34-6.

22 Bergenudd $\mathbf{H}$. Talent, occupation and locomotor discomfort [thesis]. Malmö/Lund: Malmö General Hospital and Lund University, 1989.

23 Lindgärde F, Furu M, Ljung B O. A longitudinal study on the significance of environmental and individual factors associated with the development of essential hypertension. I Epidemiol Community Health 1987; 41: 220-6.

24 Marmot M G, Rose G, Shipley M, Hamiltin P J S. Employment grade and coronary heart disease in British civil servants. I Epidemiol Community Health 1978; 32: 244-9.

25 Weinblatt E, Ruberman W, Goldberg J D, Frank C W, Shapiro S, Chaudhary B S. Relation of education to sudden death after myocardial infarction. $N$ Engl F Med 1978; 299: 60-5.

26 Onishi N, Nomura H, Sakai K, Yamamoto T, Hirayama K, Itani $\mathrm{T}$. Shoulder muscle tenderness and physical features of female industrial workers. F Hum Ergol (Tokyo) 1976; 5: 87-102.

27 Silverstein B A. The prevalence of upper extremity cumulative trauma disorders in industry [thesis]. Ann Arbor: University trauma disorders in industry [thesis]. Ann Arbor: University
of Michigan, Occupational Health and Safety Engineering, 1985.

28 Kvarnström S. Occurrence of musculoskeletal disorders in a manufacturing industry, with special attention to occupational shoulder disorders. Scand f Rehab Med Suppl 1983; 8: 6-35.

29 Hunting W, Laubli T, Grandjean E. Postural and visual loads at VDP workplaces. Ergonomics 1981; 24: 917-31.

30 Damkot D K, Pope M H, Lord J, Frymoyer J W. The relationship between work history, work environment and low-back pain in men. Spine 1984; 9: 395-9.

31 Kelsey J L, Githens P B, White A A III, et al. An epidemiological study of lifting and twisting on the job and risk for acute prolapsed lumbar intervertebral disc. $\mathcal{F}$ Orthop Res $1984 ; 2: 61-6$.

32 Frymoyer J W, Pope M H, Clements J H, et al. Risk factors in low-back pain: an epidemiological survey. $\mathcal{F}$ Bone foint in low-back pain: an epidem
Surg $[A m] ~ 1983 ; 65: .213-8$.

33 Kelsey J L, Githens P B, O'Conner T, et al. Acute prolapsed lumbar intervertebral disc: an epidemiological study with special reference to driving automobiles and cigarette special reference to driving au
smoking. Spine 1984; 9: 608-13.

34 Kellgren J H, Lawrence J S, Aitken-Swan J. Rheumatic complaints in an urban population. Ann Rheum Dis 1953; 12: $5-15$.

35 Svensson H O, Andersson G B J. Low-back pain in 40- to 47 - 
year-old men. Work history and work environment factors. Spine 1983; 8: 272-6.

36 Svensson H O, Andersson G B J. The relationship of lowtory, work environment, and stress. retrospective cross-sectional study of 38- to 64-year-old women. Spine 1989; 14: 517-22.

37 Biering-Sörensen F. A prospective study of low-back pain in (1) A prospective study of low-back pain in 38 Bjelle A, Hagberg $M$, Michaelsson G. Occupational and individual factors in acute shoulder-neck disorders among
ind , Ind Med 1981; 38: 356-63.

39 Herberts P, Kadefors R, Andersson G, Petersén I. Shoulder pain in industry: an epidemiological study on welders. Acta Orthop Scand 1981; 52: 299-306.
40 Herberts P, Kadefors R, Högfors C, Sigholm G. Shoulder pain and heavy manual labour. Clin Orthop 1984; 191: 166-78.

41 Cassel J. The contribution of the social environment to host resistance. Am $\mathcal{F}$ Epidemiol 1976; 104: 107-23.

42 Syme S L, Berkman L F. Social class, susceptibility and sickness. Am 7 Epidemiol 1976; 104: 1-8.

43 Siegrist J. Sleep disturbances and cardiovascular risk: biopsychosocial approach. In: Peter I H, Podstus T, Wichert P V, eds. Sleep related disorders and internal medicine. Berlin: Springer, 1987: 173-82.

44 Moldofsky H. Sleep and fibrositis. Rheum Dis Clin North Am 1989; 15: 91-103. 